Al-Kindy College Medical Journal (KCMJ)

Research Article

\title{
The immediate and late results for balloon angioplasty of native coarctation of aorta in pediatrics age group
}

\author{
Maitham Qasim Mohammed 1, Husam Thaaban Al-Zuhairi 1, Ameer Adnan Muhsen ${ }^{1}$, Sadiq M. Al Hamash 2 \\ 1. Ped. Cardiology. Ibn Al-Nafis cardiovascular teaching hospital., Baghdad, Iraq \\ 2. Consultant Interventional Cardiologist Al-Bitar center for cardiac surgery, Baghdad, Iraq
}

\begin{tabular}{|c|c|}
\hline & A bs r tact \\
\hline \multirow{3}{*}{$\begin{array}{l}\text { https://doi.org/10.47723/kcm } \\
\text { j.v16i2.259 }\end{array}$} & Background: percutaneous balloon dilation of corotation of the aorta is a less invasive \\
\hline & and alternative to surgical repair for patients with discrete coaction of the aorta and \\
\hline & although the use of balloon angioplasty in patients with recurrent postoperative \\
\hline \multirow{2}{*}{$\begin{array}{l}\text { Article history: } \\
\text { Received } 10 \text { June } 2020\end{array}$} & coarctation gained a wide consensus, the use of this technique for native coarctation is \\
\hline & still controversial in children less one years. \\
\hline \multirow[t]{3}{*}{ Accepted 15 November 2020} & Objective: To evaluate the immediate and late result of balloon dilation of native \\
\hline & coarctation of the aorta in infants and children. \\
\hline & Type of the study: A prospective study. \\
\hline \multirow{15}{*}{$\begin{array}{l}\text { Keywords: } \\
\text { coarctation of aorta } \\
\text { ballon angioplasty }\end{array}$} & Subjects \& Methods: The study was done on forty-five patients who were referred for \\
\hline & cardiac catheterization and balloon angioplasty of native coarctation of the aorta at Ibn- \\
\hline & AL-Bitar center for cardiac surgery between January 2015 to May 2016. Left heart \\
\hline & catheterization was performed with an evaluation of the morphology and pressure \\
\hline & gradient across the stenotic segment of the aorta. Follow-up evaluations were done \\
\hline & $\begin{array}{l}\text { between } 1 \text { week and } 18 \text { months after discharge (mean } 6 \text { months) with transthoracic } \\
\text { echocardiography. }\end{array}$ \\
\hline & Results: The age of patients ranges from 1 month to 4 years (median age at the time of \\
\hline & procedure was12.3month). Associated lesions in 11 patients $(24.4 \%)$. Immediate \\
\hline & results were a reduction in a gradient from $42.5 \pm 17.3$ to $10.3 \pm 8.2 \mathrm{~mm} \mathrm{Hg}$ in forty-two \\
\hline & patients $(93.3 \%)$. The late result during the follow-up period, 29 patients $(69 \%)$ had \\
\hline & $\begin{array}{l}\text { maintained a gradient less than } 20 \mathrm{mmHg} \text {. Complications were reported in } 6 \text { patients } \\
(13.3 \%) \text {. there was one procedure-related death }(2.2 \%) \text {. }\end{array}$ \\
\hline & Conclusions: Balloon angioplasty for treatment of native coarctation of the aorta is \\
\hline & effective with sustained benefit on long-term follow-up in infants and children $>6$ \\
\hline & months. Transverse arch hypoplasia and children $<6$ months old has a major effect on \\
\hline & the late outcome of recurrent coarctation of the aorta. \\
\hline
\end{tabular}

\section{Introduction}

Coarctation of the aorta is thought to be caused by a malformation of the aortic media that creates prominent posterior infoldings (the posterior shelf), which, in some cases, extends around the entire circumference of the aorta. The lesion is most often discrete, but it may be a long segment or tortuous in nature. In infants, particularly those with associated left ventricular outflow obstruction or a ventricular septal defect, there may be diffuse hypoplasia of the transverse aortic arch and isthmus, proximal to the discrete coarctation. Less commonly, coarctation of the aorta occurs in other locations, such as the ascending aorta or the abdominal aorta [1].
Simple coarctation describes coarctation of the aorta occurring without important intracardiac lesions, with or without a patent ductus arteriosus. The term complex coarctation is used to describe coarctation with important associated intracardiac pathology. Fifty-two percent had a simple coarctation. The remaining $48 \%$ had complex coarctation, with a large ventricular septal defect the most common associated lesion. A bicuspid aortic valve occurs in $85 \%$ of patients with coarctation, and the valve may be stenotic or annulus hypoplastic [1].

Coarctation of the aorta occurs in approximately $8-10 \%$ of patients with congenital heart disease [2]. As with most left-sided obstructive lesions, coarctation occurs more commonly in males than in females with a ratio range from 1.4:1 to $3: 1$ [3].

The clinical presentation of coarctation of the aorta generally follows one of three patterns: An infant with congestive heart failure, a child or 
adolescent with systemic arterial hypertension, or a child with a heart murmur [1]. Coarctation of the aorta tends to produce significant symptoms in early infancy. Neonate with severe juxta ductal coarctation becomes acutely symptomatic when the ductus closes [4]. Coarctation of the aorta often presents later in childhood as systolic hypertension or as a heart murmur. Delayed diagnosis beyond infancy is common because the physical findings may be subtle and most of these children are asymptomatic, minor symptoms include epistaxis and leg fatigue. Leg fatigues occur in about half of the patients, but claudication is reserved for abdominal coarctation [5].

In neonates or infants, the signs of congestive cardiac failure may be present and profound. Clinical diagnosis of coarctation of the aorta rests on the recognition of a blood pressure differential between the upper and lower extremities [6]. Several findings may be noted on palpation of the precordium. Left ventricular pressure and volume overload produce a prominent, heaving ventricular impulse at the apex. A systolic thrill may be palpable in the suprasternal notch, but the presence of a precordial thrill is unusual in isolated coarctation and should raise suspicion of an associated intracardiac lesion [1]. Coarctation of the aorta is associated with systolic, diastolic, or continuous murmurs. An ejection sound is an auscultator sign of coexisting bicuspid aortic valve. The first heart sound is normal, the second heart sound is either single or normally split, with increased intensity of the aortic component. A loud single second sound in the second left interspace is due to augmented aortic valve closure [5].

Electrocardiographic patterns fall into two groups namely, symptomatic neonatal coarctation and coarctation after childhood. Left atrial $\mathrm{p}$ wave abnormalities occur in adults and right atrial $\mathrm{p}$ wave abnormalities occur in symptomatic infants. The mean QRS axis is normal, although a leftward axis is occasionally found in older patients. Right axis deviation with right ventricular hypertrophy is typical of the electrocardiogram in symptomatic infants [5].

In symptomatic infants, significant cardiac enlargement is present, with the cardiomegaly consisting primarily of left ventricular and left atrial enlargement. The lung fields show a diffuse reticular pattern of pulmonary edema and pulmonary venous congestion. In older children cardiac size and pulmonary vasculature are normal. The roentgenographic appearance of the descending aorta is often diagnostic of coarctation of the aorta by showing post stenotic dilation. The barium swallow shows an E sign. On plain chest X-rays, often the left side of the thoracic aorta shows soft-tissue densities in the form of the number 3 that mirror the barium sign. Rib notching may be apparent in older children and adolescents, but its absence does not rule out the diagnosis of coarctation [6].

Magnetic resonance imaging images in the sagittal and parasagittal projections can clearly define the location and severity of coarctation, and the anatomy of the aortic arch. Multidetector CT angiography can also provide an excellent anatomic diagnosis in patients with coarctation and aortic arch anomalies [7]. Two-dimensional echocardiography and Doppler studies provide an accurate, noninvasive assessment of coarctation anatomy and physiology in most patients [1]. Coarctation is best imaged with high left parasternal views, with lateral angulation of the scan toward the left shoulder (the so-called ductal-coarctation view). The suprasternal notch views are used for Doppler interrogation, but they often do not display the anatomy of the coarctation well (the plane of ultrasound is parallel with the aortic wall). Doppler evaluation of coarctation is essential because two dimensions scans of the area in older patients are difficult to obtain. Color flow aliasing is present at and beyond the narrowed segment. Systolic velocity in the descending aorta is increased. The frequent association of transverse arch hypoplasia with coarctation often increases proximal velocities as well. Therefore, in coarctation, the systolic pressure gradient should be calculated only with the expanded Bernoulli equation. In severe coarctations, there is a gradient between both the systolic and diastolic pressures on either side of the stenosis. This results in a classic sawtooth pattern with the continuous flow on continuous wave Doppler interrogation. Subcostal imaging should be performed to assess the plasticity of and Doppler flow in the lower descending thoracic or upper abdominal aorta. In many older patients, echocardiography alone may not provide enough data to manage the patient confidently. In these cases, Magnetic resonance imaging usually provides an excellent anatomic evaluation of the aorta, and it can also define the presence and importance of any arterial collateral circulation that may have developed [8].

Cardiac catheterization can serve both diagnostic and therapeutic purposes in patients with coarctation of the aorta. Diagnostic cardiac catheterization is unnecessary if noninvasive evaluation (including physical examination, chest roentgenogram, echocardiogram, magnetic resonance imaging, and/or CT) clearly delineates the lesions that are present [9]. The hemodynamic severity of a coarctation often is assessed by the magnitude of its systolic pressure gradient. In a child with an isolated coarctation and a normal cardiac output, a systolic gradient $<20$ $\mathrm{mm} \mathrm{Hg}$ is generally indicative of mild coarctation [1].

The timing of coarctation repair depends on the nature of the patient's presentation [1]. In infants, coarctation presenting with heart failure demands immediate and aggressive treatment. Medical management consists of initially stabilizing the patient with inotropic support and diuretic therapy. After a brief period of medical management to stabilize the child, definitive repair should be performed [1]. Intervention in this age group usually involves surgical relief of the obstruction with excision of the area of coarctation and extended end-to-end repair or end-to-side anastomosis with absorbable sutures to allow remodeling of the aorta with time. In children, coarctation repair is generally recommended at 2 to 3 years of age in asymptomatic children without severe upperextremity hypertension. Balloon dilation is the current technique in many centers, with surgery being reserved for cases with associated arch hypoplasia [10].

In adolescent \& adult, recent recommendations from the American Heart Association/American College of Cardiology guidelines state that the coarctation of the aorta should be repaired in patients with $>20 \mathrm{~mm} \mathrm{Hg}$ peak-to-peak gradient, or in patients with $<20 \mathrm{~mm} \mathrm{Hg}$ gradient with significant angiographic/imaging evidence of a narrowing (level of evidence C) [11].

Surgical repair of coarctation can be achieved by several techniques: resection with end-to-end anastomosis, subclavian flap aortoplasty in infants with long-segment coarctation, a bypass graft across the area of coarctation when the distance to be bridged is too long for an end-to-end repair or prosthetic patch aortoplasty [12].

Balloon angioplasty has been recommended as the preferred treatment for children and adults with native coarctation or recoarctation after surgery .30 the initial success rate, defined as a gradient $\leq 20 \mathrm{mmHg}$ across the coarctation, is approximately 80 to $90 \%$ in the largest studies [13].

This study is aimed to evaluate the immediate, late result and complications of balloon angioplasty of native coarctation of descending aorta in children with different age group

\section{Subjects and methods}

A prospective study was done between January 2015 to May 2016 for 45 patients who were referred for cardiac catheterization and balloon angioplasty of native coarctation of the aorta on the recommendation of the attending pediatric cardiologist at Ibn-AL-Bitar center for cardiac surgery. Indications for dilation included angiographic evidence of significant discrete coarctation and a pressure gradient $>20 \mathrm{~mm} \mathrm{Hg}$, from ascending to descending aorta at cardiac catheterization. Diagnosis of coarctation was based upon a combination of clinical signs, noninvasive imaging echocardiography, computerized tomography (CT) scan and invasive pressure gradient measurements. Data regarding patients' clinical status were collected by direct interview with the patient's parent. 
After a detailed explanation, informed written consent was obtained from the parents of patients. General anesthesia was used in all patients. A diagnostic catheterization was performed to determine the exact morphology and the pressure gradient of the stenosis in all patients. A 5 $7 \mathrm{~F}$ catheter is advanced retrograde across the stenosis part of the aorta with the aid of an appropriate wire. Angiography was performed in different projections (frontal, lateral, and left-anterior oblique views). The diameter of the aorta was measured at the aortic isthmus, at the site of obstruction, and in the descending aorta at the level of the diaphragm. Once measurements were made and recorded, we decided the appropriate balloon size and give intravenous heparin $(50 \mathrm{IU} / \mathrm{kg}$, maximum of $2000 \mathrm{IU}$ ). We used a single balloon catheter (Tyshak, NuMED Inc) with a diameter no greater than the aortic diameter at the level of the diaphragm or 1-2 mm larger than the aortic isthmus. The balloon catheter is advanced across the CoA with the aid of an appropriate J-tipped exchange wire (0.018 to 0.035 ), and the soft tip of the wire was located deep in the right subclavian artery or left ventricle. The deflated balloon is placed across the coarctation and is inflated until the waist disappears and this is repeated 3 to 5 times each for 10 to 15 seconds. The balloon catheter was replaced (over the guide-wire) with a multipurpose catheter. Ascending, transverse, and descending aortic pressures were remeasured by a pullback to obtain a post balloon angioplasty gradient. The procedure was considered successful if the invasive gradient was reduced to $<20 \mathrm{mmHg}$. Before discharge, all patients underwent complete clinical evaluation and echocardiography. The period of follow-up was from 1week - 18 months (mean 6 months).

\section{Statistical Analysis}

The SPSS statistical program for Windows, version 20(SPSS Inc., Chicago, Illinois, USA) was used to perform data analysis. The Student paired ttest was used to compare preangioplasty and postangioplasty pressure gradients. A p-value $<0.05$ was considered statistically significant. the follow-up pressure data are expressed as mean value $\pm S D$, and length of follow-up is expressed as the median value and range in months. For categorical data, chi-square analysis was used.

\section{RESULTS}

The studied group includes 45 patients with coarctation of the aorta. Twenty-five patients were male (55.6\%) and twenty patients were female $(44.4 \%)$ with a male: female ratio of $1.25: 1$. There was no significant difference between the two sex $(p>0.03)$.

The patient's ages ranged from 1 month to 4 years (median age at the time of procedure was 12.3 month). There were 19 infants $<6$ months old, ( 4 of who were neonates), 10 infants were between 7 months to 1 year old and 16 children were $>1$ year old.

There were associated lesions in 11 patients $(24.4 \%)$ apart from the bicuspid aortic valve which was found in 27 patients (60\%), the most common lesion was PDA in 7 patients $(15.5 \%)$ and the 2 nd most common lesion was VSD in 4 patients $(8.8 \%)$.

LV dysfunction was recorded in 4 patients (8.8\%), 2 of them had COA with other association lesions while the other 2 patients had isolated COA.

The mean procedure time was $(60.8 \pm 20.9)$ min. and the mean fluoroscopy time was $(17.9 \pm 4.7) \mathrm{min}$.

The average peak systolic gradient was reduced from $42.5 \pm 17.3 \mathrm{~mm} \mathrm{Hg}$ before the procedure to $10.3 \pm 8.2 \mathrm{~mm} \mathrm{Hg}$ after the procedure ( $\mathrm{p}<$ 0.001).

Forty-two patients(93.3\%) of patients had successful dilation Two patients (4.4\%) had an unsuccessful dilation (one neonate and another patient 1.5year ) and there was one procedure-related death (2.2\%) (age of 1.2 years) (Table 1) Of the 42 patients who initially had a successful angioplasty, 29 patients $(69 \%)$ have success dilation for a follow-up period of 1 weak to 18 months (median 6 months) and 13 patients (31\%) developed recurrence of coarctation. Nine patients (50\%) of 18 patients $<6$ months included all neonates who initially had successful angioplasty developed recurrence of coarctation during the period of following between 1 week to $4 \mathrm{~m}$ (median $1 \mathrm{~m}$ ). Two patients (20\%) of 10 patients (6-12 months) who initially had successful angioplasty develop recoarctation 1weeke to 6 months (median $3.1 \mathrm{~m}$ ) later. Two patients (14.3\%) of 14 child (>1 years) who initially had successful angioplasty develop recoarctation 1 to 18 months (median 10) later. (Table 2).

If we compare between patient $<6 \mathrm{~m}$ and patient $>6 \mathrm{~m}$ we found the late recurrence rate was $50 \%$ ( $\mathrm{P}$ value 0.008 ) in patient $<6 \mathrm{~m}$ while the late recurrence rate was $16.7 \%$ ( $\mathrm{P}$ value 0.682 in patient $>6 \mathrm{~m}$. (Table 3 ).

A transverse arch and isthmic hypoplasia were found in 12 patients with immediate success in $10(83.3 \%)$ compared with those without hypoplasia which was in 32 patients with success in all patients $(100 \%)$. A greater incidence of late recurrence of COA was in 8 patients $(80 \%)(\mathrm{P}$ value 0.002 ) with hypoplasia while patients without hypoplasia incidence of late recurrence of COA in 5 patients (15.6\%) (P value 0.14 ). (Table 4).

complications were reported in 6 patients (13.3\%). there was one procedure-related death $(2.2 \%)$. An intimal tear had recorded in 2 patients (4.4\%). Three patients (6.6\%) complained of loss of femoral pulse which was treated with intravenous heparin where femoral pulse returns to normal within $24 \mathrm{~h}$., these complications had not led to a major sequel.

Table 1.:Patients Grouped According to their Age and Immediate result of Angioplasty.

\begin{tabular}{cccc}
\hline Age group & $\begin{array}{c}\text { No. Of } \\
\text { patient }\end{array}$ & $\begin{array}{c}\text { Successful } \\
\text { (immediate } \\
\text { result) }\end{array}$ & $\begin{array}{c}\text { Failure } \\
\text { (immediat } \\
\text { e result) }\end{array}$ \\
\hline$<6 \mathrm{~m}$ & 19 & $18(94.7 \%)$ & $1(5.3 \%)$ \\
$6 \mathrm{~m}$-1year & 10 & $10(100 \%)$ & $0(0 \%)$ \\
$>1$ year & 16 & $14(87.5 \%)$ & $2(12.5 \%)$ \\
TOTAL NO. & 45 & $42(93.3 \%)$ & $3(6.7 \%)$ \\
\hline
\end{tabular}

Table 2. :Patients Grouped According to their Age, late result of Angioplasty and length of follow up.

\begin{tabular}{ccccc}
\hline Age group & $\begin{array}{c}\text { No. of } \\
\text { patient }\end{array}$ & $\begin{array}{c}\text { Successful (late } \\
\text { result) }\end{array}$ & $\begin{array}{c}\text { Recurrence } \\
\text { (late result) }\end{array}$ & $\begin{array}{c}\text { Median time to } \\
\text { failure(month) }\end{array}$ \\
\hline$<6 \mathrm{~m}$ & 18 & $9(50 \%)$ & $9(50 \%)$ & $0.25-4(1)$ \\
$6 \mathrm{~m}-1$ year & 10 & $8(80 \%)$ & $2(20 \%)$ & $0.25-6(3.1)$ \\
$>$ 1year & 14 & $12(85.7 \%)$ & $2(14.3 \%)$ & $2-18(10 \mathrm{~m})$ \\
TOTAL N0. & 42 & $29(69 \%)$ & $13(31 \%)$ & $0.25-18(6 \mathrm{~m})$ \\
\hline
\end{tabular}

Table 3: One-sample T-test shows the frequency and percentage of failure between age groups.

\begin{tabular}{llllll}
\hline $\begin{array}{l}\text { Age } \\
\text { group }\end{array}$ & $\begin{array}{l}\text { Total } \\
\text { number }\end{array}$ & $\begin{array}{l}\text { Frequency } \\
\text { of failure }\end{array}$ & $\begin{array}{l}\text { Percentage } \\
\text { of failure }\end{array}$ & $\begin{array}{l}\text { Mean } \\
\pm \text { SD }\end{array}$ & $\begin{array}{l}\text { P. } \\
\text { value }\end{array}$ \\
\hline $\begin{array}{r}\text { < } \\
\text { months }\end{array}$ & \multirow{2}{*}{18} & 9 & $50 \%$ & $\begin{array}{l} \pm 4.78 \\
\pm\end{array}$ & $0.008^{*}$ \\
& & & & 34.66 & \\
$>\quad 6$ & & & & 18.21 & \\
months & 24 & 4 & $16.7 \%$ & $\begin{array}{l} \pm \\
21.154\end{array}$ & $0.682^{* *}$ \\
\hline
\end{tabular}

*P. value equal or less than 0.05 is statistically significant 
Table 4: One-sample T-test shows the frequency and percentage of failure between patients who had transverse arch hypoplasia or without hypoplasia.

\begin{tabular}{ccccc}
\hline & $\begin{array}{c}\text { No. of } \\
\text { patient }\end{array}$ & $\begin{array}{c}\text { Immediate } \\
\text { success }\end{array}$ & Recurrence & P value \\
\hline $\begin{array}{c}\text { With } \\
\text { hypoplasia }\end{array}$ & 12 & $10(83.3 \%)$ & $8(80 \%)$ & 0.002 \\
$\begin{array}{c}\text { Without } \\
\text { hypoplasia }\end{array}$ & 33 & $33(100 \%)$ & $5(15.6 \%)$ & 0.14 \\
\hline
\end{tabular}

*P. value equal or less than 0.05 is statistically significant

\section{DISCUSSION}

The male/female ratio was 1.25:1 \& the percentage of male patients was (55.5\%) which is compatible with other studies as male predominant as the Michael et al (Texas children's hospital), Galal et al (King Fasil special hospital), and AL-Nasiry and AL-Hamish (Ibn Al-Bitar cardiac center) studies $(63 \%, 62 \% \& 74.2 \%)$ respectively $[14,15,16]$. This proved the fact that all left-sided lesions more common in males than females.

The ranged age of all patients was (1m to 4years) which is near the range age of the Michael et al study [14]. (1m to $31 \mathrm{~m})$, but less than the age of patients in Galal et al study [15] (2days to 15years) years and ALNasiry and AL-Hamash study [16] (1m to 45 years).

Apart from the bicuspid aortic valve which was the most common in all studies, in our study the most common lesion was PDA and the second most common lesion was VSD. In AL-Nasiry and AL-Hamash study the most common lesion was aortic stenosis and the second most common lesion was PDA while in Michael et al study the most common lesion was VSD and the second most common lesion was PDA [14,15].

A significant number of LV dysfunction was compatible with AL-Nasiry and AL-Hamash study and caused by obstruction or shunt lesion [16].

The mean procedure time was $(60.8 \pm 20.9) \mathrm{min}$. which is nearly similar to the mean procedure time of the Michael et al study $(55 \pm 22)$ min and Galal et al study $(56 \pm 17.3)[14,15]$.

The mean fluoroscopy time was $(17.9 \pm 4.7)$. min which is nearly similar to the mean fluoroscopy time of the Michael et al study $(15 \pm 6)$ min and Galal et al study (18.1 \pm 4.2$)[14,15]$.

Our immediate success rate was $93.10 \%$ which is in agreement with Michael et al and Galal et al studies (92\% and 100\%) respectively $[14,15]$. On the other hand, it is higher than AL-Nasiry and AL-Hamash study (81.3\%) [16] Which was done in the same center and this may reflect an improvement in the skills of the operator.

Follow-up result. the success rate was $69 \%$ and it is near the result of Michael et al and Galal et al studies (75\%,77.2\%) respectively [14,15]. Infant less than $6 \mathrm{~m}$ have fared less well in the intermediate follow-up. Despite the immediate success of $94.7 \%$, but $50 \%$ of these patients had developed a recurrence of COA. The results in this study are similar to Michael et al and Galal et al studies [14,15].

Our angiographic data suggest that transverse arch hypoplasia may have a major role in predicting the immediate or late angioplasty gradient. A transverse arch and isthmic hypoplasia were associated with immediate gradients $>20 \mathrm{~mm} \mathrm{Hg}(16.6 \%)$ compared with those without hypoplasia $(0 \%)$ and a greater incidence of late gradients $(80 \%$ vs. $15.6 \%)$ in the group with hypoplasia as compared with those without hypoplasia. In Michael et al study the transverse arch hypoplasia considers as a minor role in predicting the immediate or late angioplasty gradient [14]. complications were occurred in 6 patients (13.3\%). there was one procedure-related death $(2.2 \%)$. An intimal tear had recorded in 2 patients while in AL-Nasiry and AL-Hamash study is recorded in 7 patients. Three patients complained of loss of femoral pulse in the catheterized leg and all these patients there was the reappearance of the pulse within 24h, while in Michael et al, Galal et al and AL-Nasiry and ALHamash study it was in $(10,4,5)$ patients respectively. There was no need for blood transfusion, unlike Galal et al study which was needed in 2 patients. There were no major complications of cerebrovascular accident and late aneurysm while Michael et al study show major complications with 2 patients with cerebrovascular accident and 4 patients who had a late aneurysm $[14,15,16]$.

\section{CONCLUSION}

Balloon angioplasty for treatment of native coarctation of the aorta is effective in most infants and children with sustained benefit on longterm follow-up in infants and children $>6$ months old Infant $<6$ months and Neonatal balloon angioplasty is effective but provides palliative treatment in the majority of them, and most patients will require another intervention.

Transverse arch hypoplasia and children $<6$ months old has a major effect on the outcome.

\section{Funding}

This research did not receive any specific fund.

\section{Conflicting Interest}

No conflict of interest.

\section{REFERENCES}

[1] Robert HB. Coarctation of aorta. In: Hugh DA, David JD, Timothy FF, etal,eds.Moss\&Adamsheartdiseaseininfant,children\&adolescents,7th ed,Philadelphia,Lippincott Williams\&Wilkins,2008:987-1005.

[2] Hasan AF, Manaf JY. Coarctation of aorta in paediatric age group; mode of presentation \&management outcome. Thesis summited to scientific council of cardiology. 2001; 1:3.

[3] Loffredo CA, Chokkalingam A, Sill AM, et al. Prevalence of congenital cardiovascular malformations among relatives of infants with hypoplastic left heart, coarctation of the aorta, and d-transposition of the great arteries. Am J Med Genet A 2004; 124:225-230.

[4] Gutgesell HP, Barton DM, Elain KM. Coarctation of aorta in neonate. Am J cardiol 88: 457, 2001.

[5] Joseph K. Perloff. Coarctation of aorta. Clinical recognition of congenital heart diseases, 5th ed, Philadelphia, Saunders, 2003: 113140 .

[6] Walter H J, James H M. Coarctation of aorta. Pediatric cardiology, 1st ed,Oxford, Blackedwell, 2008:137-146.

[7] Nielsen JC, Powell AJ, Gauvreau K, et al. Magnetic resonance imaging predictors of coarctation severity. Circulation 2005; 111:622-28.

[8] Silvilairat S, Cabalka AK, Cetta F, et al. Abdominal aortic pulsation and pulse delay in coarctation of the aorta: Pulse wave Doppler analysis reliably reflects severity. Journal of the American Society of Echocardiography, 2005; 18:563.

[9] Robert JS. Intervention for pediatric \& adult congenital heart disease. In: Donald SB, ed. Grossman's cardiac catheterization, angiography\& intervention, 7th ed, Philadelphia ,William \&Wilkins , 2006:605-34.

[10] Gary DW, Jeffrey FS, Judith T, et al. Congenital heart disease. In: Peter L, Robert OB, Douglas LM, et al, eds. Braunwald's heart disease: A textbook of cardiovascular medicine. 8th ed, Philadelphia, Saunders, 2007:1572-1621.

[11] Warnes CA, Williams RG, Bashore TM, et al. ACC/AHA 2008 Am guidelines for the management of adults with congenital heart disease. J Coll Cardiol. 2008; 52:143-263.

[12] Siddiq AK, Mohammed MS. Coarctation of the aorta. thesis submitted to scientific council of thoracic \& cardiovascular surgery.1998; 1:7-9.

[13] Shaddy RE, Boucek MM, Sturtevant JE et al. Comparison of angioplasty and surgery for unoperated coarctation of the aorta. Circulation 1993; 87:793-799.

[14] SCOTT E. FLETCHER, MD, MICHAEL R. NIHILL, MD, FACC, RONALD G. GRIFKA, MD, MARTIN P. O'LAUGHLIN, MD, FACC, CHARLES E. MULLINS, MD, FACC, Balloon Angioplasty of Native Coarctation of the Aorta: Midterm Follow-Up and Prognostic Factors. 
[15] SYAMASUNDAR RAO, MD, FACC -tf OMAR GALAL, MD, PHD, PATRICIA A. SMITH, RN, MN, ALr,EN D. WILSON, MD, FACC, Madiron, Wsconsin; Riyadh. Saudi Arabia: Five- to Nine-Year Fallow-Up Results of Balloon Angioplasty of Native Aortic Coarctation in Infants and Children.

[16] Sadiq Mohammed AL-Hamash,Zuhair AL-Nasiry,immediate results of balloon angioplasty for native coarctatation of the aorta ,20042005.

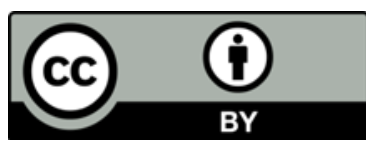

This article is an open access article distributed under the terms and conditions of the Creative Commons Attribution (CC BY)

license (http://creativecommons.org/licenses/by/4.0/) 